\title{
FORMAÇÃO DOCENTE INICIAL E CONTINUADA: DESAFIOS DA EDUCAÇÃO ESPECIAL NA PERSPECTIVA INCLUSIVA
}

\author{
Simone Maria Alves de Lima - PPGE/UFT \\ simali.semed@gmail.com \\ Luciana Pereira de Sousa - PPGE/UFT \\ lucianap@mail.uft.edu.br \\ Profa. Dra. Carmem Lucia Artioli Rolim (Orientadora) - PPGE/UFT \\ carmem.rolim@uft.edu.br
}

\begin{abstract}
RESUMO
O presente trabalho teve como objetivo analisar no âmbito da educação básica a aplicabilidade da proposta formativa para educação especial na perspectiva da educação inclusiva. Trata-se de uma investigação qualitativa que teve como procedimentos metodológicos à pesquisa documental, entrevistas semiestruturadas e pesquisa bibliográfica. A pesquisa documental possibilitou a análise de documentos elaborados pelo MEC. A pesquisa bibliográfica oportunizou uma revisão da literatura relacionada à temática em estudo e as entrevistas semiestruturadas foram realizadas com professores regentes e do atendimento educacional especializado da rede municipal de Palmas, Tocantins e comportaram subsidiar as análises de acordo com os objetivos da pesquisa. Nessa realidade questionamos acerca da formação que baseia a ação, a articulação e a orientação realizada pelo professor do atendimento educacional especializado aos professores regentes, bem como identificar nessa realidade as demais atividades formativas que subsidiam o fazer pedagógico. As proposições da concepção históricocultural fundamentam as análises. Os resultados possibilitam pontuar que a atual conjuntura política coloca as instituições de educação básica e de ensino superior ante aos desafios de reestruturação de espaço físico e propostas pedagógicas e de repensar os tempos e espaços pedagógicos para o atendimento a discentes e docentes.
\end{abstract}

Palavras-chave: Política de Inclusão. Formação. Docente.

\section{TEIAS DA INCLUSÃO: PERSPECTIVAS FORMATIVAS}

Historicamente a luta pela equidade social e a elaboração de documentos internacionais em prol do reconhecimento dos direitos das pessoas com deficiências coloca a luz das discussões o paradigma da inclusão exigindo definições e ações políticas rumo à construção de identidade e valorização desses sujeitos que, até então, se situavam à margem da sociedade no que se refere ao trabalho, esporte, lazer, educação entre outros. A discussão propõe possibilidades de reconhecimento desses, enquanto cidadãos dignos e sujeitos de suas próprias ações.

Dentre as leis internacionais que provocam discussões acerca da temática destacam-se a Declaração Universal dos Direitos Humanos, 1948; o Pacto Internacional dos Direitos Econômicos, Sociais e Culturais, 1966; a Convenção sobre os Direitos da Criança, 1989; a Conferência Mundial sobre Educação para Todos em 1990 e o 


\section{SEMINÁRIO DE PESQUISA EM CIÊNCIAS HUMANAS - SEPECH \\ Humanidades, Estado e desafios didático-científicos \\ Londrina, 27 a 29 de julho de 2016}

Relatório para a UNESCO da Comissão Internacional sobre Educação para o Século XXI, 1996.

No que diz respeito à legislação nacional que versa sobre o direito das pessoas com deficiências, especificamente, as que se referem à educação, entra em evidência a própria Constituição Federativa do Brasil de 1998 (BRASIL, 1998), destacando em seu Art. 205 a educação como direito de todos, no Art. 206 dispõe sobre os princípios da igualdade de condições para acesso e permanência na escola, no Art. 208 discorre sobre o dever do estado quanto à educação, evidenciando o atendimento educacional especializado na rede regular de ensino.

Da mesma forma, a Lei de Diretrizes e Bases da Educação Nacional (BRASIL, 1996) em seu Art. $3^{a}$ reafirma os princípios de igualdade e condições para o acesso e permanência, no Art. $4^{\circ}$ define o dever do estado para com a educação especial. Nessa construção, são elaborados decretos que aprovam, promulgam e ou regulamentam decisões internacionais e ou nacionais.

Contudo, para tratarmos da formação docente consideramos o disposto na Resolução nº CNE/CEB de 2009 (BRASIL, 2009), que Institui Diretrizes Operacionais para o Atendimento Educacional Especializado na Educação Básica, modalidade Educação Especial, que de acordo com o Art. $8^{\circ}$, Parágrafo único, o financiamento da matrícula no Atendimento Educacional Especializado (AEE) é condicionado à matrícula no ensino regular da rede pública.

Em sequência o Art. $9^{\circ}$ dispõe que a elaboração e a execução do plano de AEE são de competência dos professores que atuam na sala de recursos multifuncionais ou centros de AEE, em articulação com os demais professores do ensino regular, com a participação das famílias e em interface com os demais serviços setoriais da saúde, da assistência social, entre outros necessários ao atendimento; o Art. 10 dispõe que o projeto pedagógico da escola de ensino regular deve institucionalizar a oferta do AEE prevendo na sua organização professores para o exercício da docência do AEE; indica ainda a necessidade de tradutor e intérprete de Língua Brasileira de Sinais, guiaintérprete e demais profissionais para atuação no apoio, principalmente às atividades de alimentação, higiene e locomoção. Já no Art. 12 legisla sobre a atuação do professor que deve ter uma formação inicial que o habilite para o exercício da docência em sala de aula, bem como a formação específica para atuar na Educação Especial.

De acordo com o exposto, as instituições de ensino superior exercem papel fundamental devendo assumir a responsabilidade da oferta de cursos e ou disciplinas da educação especial nas diversas áreas da formação de modo a habilitar os diferentes profissionais. Essa responsabilidade ultrapassa os limites da oferta, de modo que é necessário, também, acompanhar; para entender o processo em âmbito nacional.

Às instituições de educação básica cabem, cultivar uma proposta de formação continuada e o presente documento abaliza em seu Art. $9^{\circ}$, sobre a responsabilidade do professor de AEE em elaborar e executar um plano de atendimento em articulação com os demais professores. Ponto em que indagamos: se ao professor de AEE cabe à formação específica para atuar na área, seria ele o responsável por disseminar tal saberes aos demais? Essa articulação se caracterizaria formação continuada? Na prática, como essa articulação se condiz em ação?

Questões que têm provocado pesquisadores a identificarem quantitativamente as instituições que ofertam cursos e ou disciplinas e que se voltem de alguma forma a habilitar profissionais para essa modalidade. Direta ou indiretamente o tema se estende 


\section{SEMINÁRIO DE PESQUISA EM CIÊNCIAS HUMANAS - SEPECH \\ Humanidades, Estado e desafios didático-científicos \\ Londrina, 27 a 29 de julho de 2016}

à formação continuada no âmbito da escola e à articulação e ações prevista na legislação.

De acordo com Bueno (2002), em 1998 as instituições que ofertavam algum tipo de formação em nível de graduação plena concentravam-se, na maioria, nas regiões sul e sudeste e a maior parte destes cursos se destinavam a formação de professores generalista e ou a especificidade de deficiência mental. Os cursos que contemplavam outras especificidades foram identificados em número reduzido ante a necessidade e ao compromisso legal. Sendo que na região norte do país não houve registro de nenhum tipo de oferta de curso na área de educação especial.

Ao voltamos o olhar à disposição do currículo dos cursos de educação, buscamos identificar a oferta de disciplinas e identificamos uma leve ampliação dessa oferta, porém, ainda insuficiente para atender a demanda. Bueno (2002, p. 31) ressalta que dentro das ações voltadas ao ensino, no que se refere à inserção de disciplinas e de núcleos temáticos nos cursos de formação de educadores das IES brasileiras a partir da Declaração de Salamanca, 1994, prega-se a inclusão dos alunos com deficiências nas classes de ensino regular, o que pressupõe um mínimo de formação por parte dos profissionais da educação.

O número de IES que ofertavam em 1998, disciplinas de educação especial nos cursos de formação de professores polivalentes era bem maior que as que ofertavam cursos nessa área, porém, boa parte destas disciplinas, destinava-se à oferta não obrigatória. Mais uma vez, focalizando a região norte, campo em que se encontra situada o universo micro de nossa pesquisa, é possível pontuar que apenas duas universidades declararam ofertar disciplina na área da educação especial, ambas de caráter obrigatório. "Essa situação parece indicar certa vanguarda com relação à inserção da educação especial na formação do professor das séries iniciais do ensino fundamental". (BUENO, 2002, p. 34). Destacamos, porém, que no estado do Tocantins até 1998, não constava oferta de cursos e nem de disciplinas de educação especial em programas para a formação de professores.

Ampliando a investigação, adentramos a disciplina de educação especial nas diferentes licenciaturas que se destinam a formação de professores para atendimento a alunos do $6^{\mathrm{a}}$ ao $9^{\mathrm{a}}$ ano e ou ensino médio. A esse respeito, Bueno $(2002$, p. 38) enfatiza que a oferta cai significativamente e que "A maior parte das disciplinas oferecidas eram eletivas, o que significa que muitos dos alunos de licenciatura não tiveram qualquer contato com conteúdos relacionados à educação especial”.

Buscando aprofundar o tema encontramos com Araújo (2010), estudos bibliográficos detalhados, destinados a captar dados a partir de alguns descritores e de artigos publicados até 2010. Esses descritores contribuíram significativamente para as análises da inserção do tema referentes às pessoas com necessidades especiais, pois indicam que,

A formação dos profissionais da Educação, ainda parece prevalecer uma valorização da formação continuada, embora a preocupação com a formação inicial já esteja presente [...] e que o processo de formação dos professores sobre a inserção das pessoas com deficiências no ambiente escolar, a discussão se mantém de forma generalista. (ARAÚJO, 2010. Grifos nossos). 


\section{SEMINÁRIO DE PESQUISA EM CIÊNCIAS HUMANAS - SEPECH \\ Humanidades, Estado e desafios didático-científicos \\ Londrina, 27 a 29 de julho de 2016}

Considerando a Política Nacional de Educação Especial na perspectiva da Educação Inclusiva (BRASIL, 2008) a qual reconhece os alunos com necessidades educacionais especiais (NEE), aqueles com deficiências, transtornos globais de desenvolvimento e altas habilidades/superdotação e se volta a orientar e articular uma proposta de educação especial ao ensino regular. Estabelece, ainda, o atendimento às necessidades educacionais especiais de alunos incluídos na escola regular e sob a qual versa que a formação de professores para o atendimento educacional especializado em nível de especialista, deixa subtendido a responsabilidade desse profissional ante a organização, articulação e orientação no âmbito da escola. Contudo, ao não dispor sobre os aspectos formativos dos demais professores do ensino regular, percebe-se um descompasso da proposta.

Realidade que nos provoca a analisar no contexto escolar a aplicabilidade da proposta formativa para educação especial na perspectiva da educação inclusiva a partir da visão e ação dos professores envolvidos.

\section{DESEMARANHANDO AS TEIAS: O CAMINHO DA PESQUISA}

O presente trabalho trata-se do recorte de uma investigação qualitativa realizada na cidade de Palmas, TO no período de 2012 a 2014. Os dados aqui expostos são uma continuidade de nossa pesquisa para o mestrado. Trata-se de discussões e análises acerca do processo de formação docente a partir da percepção do próprio professor, que na época não eram objeto do estudo, mas por se revelarem importantes nos propusemos a compartilhá-los e discuti-los a partir do presente texto.

Definimos como processo metodológico a observação participante e como procedimentos à pesquisa documental, entrevistas semiestruturadas e pesquisa bibliográfica. A pesquisa documental possibilitou a análise de documentos elaborados pelo Ministério da Educação (MEC). A pesquisa bibliográfica oportunizou uma revisão da literatura relacionada à temática em estudo e as entrevistas semiestruturadas foram realizadas com professores regentes e do atendimento educacional especializado, essas possibilitaram entender a realidade a partir do relato dos próprios docentes.

Como recursos, recorremos às gravações audiovisuais e aos questionários. A opção pela "observação participante" vem do entendimento que essa possibilita uso de recursos variados o que possibilitou a recolha e a análise no decorrer da investigação. A definição dos sujeitos professores de matemática de $6^{\circ}$ ao $9^{\circ}$ ano e professores do atendimento educacional especializado possibilitaram análises e aproximações da proposta política e da efetiva ação desses no contexto escolar.

Dessa forma a recolha dos dados se deu em momentos e em espaços distintos, no entanto, completam-se e substanciam os resultados. De acordo com Triviños (1990), ao não estabelecer separações estanques entre a coleta e a interpretação das informações, o autor indica encaminhamentos entre as informações levantadas e a análise, podendo dar origem a novas questões, o que possibilita uma nova busca de dados.

Segue ainda orientações de Bogdan e Biklen (1994), ao disporem que a investigação qualitativa tem em sua essência cinco características que definem $o$ interesse da pesquisa. A fonte direta de dados como ambiente natural e o investigador como instrumento principal na coleta desses dados constituem a primeira característica, os dados recolhidos como carácter descritivo, a segunda, os investigadores que utilizam metodologias qualitativas, mais interessados no processo que nos resultados, a terceira, 


\section{SEMINÁRIO DE PESQUISA EM CIÊNCIAS HUMANAS - SEPECH \\ Humanidades, Estado e desafios didático-científicos \\ Londrina, 27 a 29 de julho de 2016}

a análise dos dados de forma indutiva, a quarta e o investigador mais interessado no significado que os participantes atribuem às suas experiências do que pela própria experiência, a quinta.

Para o presente estudo consideramos os dados coletados no início da pesquisa na testagem dos instrumentos e os dados coletados no decorrer da investigação o que resultou no total de quinze professores do atendimento educacional especializado e sete professores de matemática que lecionavam de $6^{\circ}$ ao $9^{\circ}$ e que tinham em suas turmas alunos com necessidades educacionais especiais ${ }^{1}$. A coleta a partir da aplicação de questionário junto aos professores de AEE se deu em uma formação e embora houvesse outros professores, apenas quinze atendiam alunos de $6^{\circ}$ ao $9^{\circ}$ anos.

Com os professores de matemática foram realizadas entrevistas individualizadas durante o planejamento e em escolas distintas. A coleta de dados, em diferentes espaços possibilitou uma visão micro da realidade investigada, sobre a qual passamos a dispor.

\section{AÇÃO FORMATIVA E INCLUSÃO: APROXIMAÇÕES E DISTANCIAMENTOS}

Retomando o Art. 8º, Parágrafo Único da Resolução no 4 CNE/CEB 2009 (BRASIL, 2009) verificamos que a matricula no AEE é condicionada a matricula no ensino regular, fato que coloca os professores do ensino regular ante ao desafio de efetivar a atividade educativa para um público que requer ações, métodos e recursos diferenciados. Considerando o Art. $9^{\circ}$ da mesma Resolução que delibera sobre a responsabilidade do professor do AEE elaborar em articulação com os demais professores, família e setores o plano de atendimento.

Entendemos que o referido plano deva contemplar a especificidade do educando e o processo de ensino-aprendizagem tanto na sala de recursos multifuncionais, quanto na sala de ensino regular. Se considerarmos a quantidade de professores e de disciplinas que compõem o âmbito educacional identificamos um universo extenso e repleto de desafios. Contexto que se desvela repleto de dilemas, sendo esses explicitados pelos dados da pesquisa.

Direcionando o olhar aos quinze professores do AEE que participaram da investigação: dois declararam dialogarem e articularem o trabalho, porém, não deixaram claro em que momento e situação realizam essa articulação; três disseram que dialogam com os professores em momentos pontuais, geralmente na sala dos professores; um disse planejar com o professor auxiliar e ser esse professor o responsável por fazer a ponte entre a sala de recursos e sala de aula regular; uma não respondeu e oito declararam não haver articulação por falta de organização do tempo e espaços pedagógicos, descreveram a rotina relatando a quantidade de alunos atendidos $\mathrm{e}$ afirmam não sobrar tempo para essa articulação.

Quando é destacado o momento de dificuldade os professores citam a quantidade de disciplinas e de professores e o fato de os planejamentos se darem em dias e horários diferenciados o que compromete o tempo para a articulação entre os

\footnotetext{
${ }^{1}$ O presente estudo considera os alunos com necessidades educacionais especiais o disposto pela Política Nacional de Educação Especial na Perspectiva da Educação Inclusiva, ou seja, "os alunos com deficiência, transtornos globais de desenvolvimento e altas habilidades/superdotação" (BRASIL, 2008, p. 15).
} 


\section{SEMINÁRIO DE PESQUISA EM CIÊNCIAS HUMANAS - SEPECH \\ Humanidades, Estado e desafios didático-científicos \\ Londrina, 27 a 29 de julho de 2016}

pares. Dos sete professores da sala de aula regular, cinco declaram não haver articulação, um ressalta diálogos pontuais e outro considera haver certa articulação. Os motivos apontados como complicadores ao processo são os mesmos destacados por todos, ou seja, a falta de uma organização de horário para o planejamento colaborativo.

Quanto à formação, dos quinze professores do AEE, menos da metade possuía formação especifica em educação especial e a maioria declarou ter formação em algum tipo de deficiência. $\mathrm{O}$ que prenuncia necessidade de estudos para o atendimento na própria sala de recursos.

Todos os professores de matemática afirmaram não possuírem formação e nem tão pouco cursaram disciplinas referentes ao tema em sua formação inicial, afirmaram não haver formação continuada e assinalam a ineficiência da proposta quanto à formação, pois os cursos e seminários referentes ao tema contemplam apenas os professores do AEE.

Ao colocamos em questão "outras atividades formativas" evidenciam-se no âmbito da escola as experiências e trocas dessas nos espaços de convivência entre os docentes. Alguns revelaram buscar informações na internet, contudo, asseguram o comprometimento do processo uma vez que desconhecem a forma de aprender e os recursos e ou instrumentos necessários a cada especificidade: deficiência auditiva (DA), deficiência física (DF), deficiência mental (DM), as síndromes, transtornos e altas habilidade/superdotação, evidenciam o aumento de dificuldade quando em mesma turma são matriculados alunos com diferentes especificidades.

Nessa realidade, no que se refere à discussão sobre educação especial, conferimos um impulso discursivo e a elaboração de documentos que se voltam a orientar a interface educação especial e ensino regular. No entanto, os avanços propostos pela legislação não condiz em adequações do currículo que se volte a atender os objetivos da educação em geral e da educação especial. Parafraseando Vigotski (1997, p. 59):

O trabalho, portanto, permanece até o presente momento sem vinculação teórica nem prática com as bases gerais da educação social e com o sistema de educação pública de nossa república. A tarefa consiste em vincular a pedagogia da infância das crianças com deficiências: pedagogia de surdos, cegos, deficientes intelectuais, etc. com os princípios e métodos gerais da educação social; encontrar tal sistema, que permita ligar organicamente a pedagogia especial com a pedagogia da criança normal. Aguarda-nos um grande trabalho criativo para reestruturar nossa escola sobre as bases de novos princípios. Devemos esboçar as linhas básicas ou, para falar com mais exatidão, os pontos de partida, para esse trabalho.

Essa organização só se efetivará quando todos os envolvidos tiverem formação que os capacitem para a atividade docente. $\mathrm{O}$ que pressupõe pensar e implementar o conceito de escola inclusiva. Que de acordo com Marchesi (2004, p.15), "escolas inclusivas supõe uma maneira mais radical de entender a resposta educativa à diversidade dos alunos e baseia-se fundamentalmente na defesa de seus direitos [...]". Diante do exposto observa-se uma grande preocupação em proporcionar encaminhamentos para efetivação da política de educação especial, no entanto, as propostas, principalmente a formativa, não têm se efetivado em prática. Situação que 


\section{SEMINÁRIO DE PESQUISA EM CIÊNCIAS HUMANAS - SEPECH \\ Humanidades, Estado e desafios didático-científicos \\ Londrina, 27 a 29 de julho de 2016}

gera desafios e compromete o fazer pedagógico, processo de ensino-aprendizagem e em consequência o desenvolvimento dos educandos com necessidades especiais.

\section{CONSIDERAÇÕES FINAIS}

Ao trazer o olhar do professor, entendemos que o sistema educacional já é repleto de responsabilidades e compromissos e que a proposta da educação inclusiva lança novos desafios às Instituições de Ensino Superior como também à Educação Básica, principalmente, no que se referem à formação, investimentos e na reorganização do currículo, métodos e metodologias. A escola para todos requer uma dinamicidade curricular que permita ajustar o fazer pedagógico às necessidades dos alunos, sendo a formação o ponto de partida do processo à medida que essa é fundamental para orientar a prática educativa.

Dessa forma, para que os docentes possam oportunizar o processo de ensinoaprendizagem e atenderem as necessidades dos alunos considerando suas especificidades é imprescindível que se repense, a reestruturação curricular, os processos formativos e as estruturas organizacionais das instituições tanto do Ensino Superior quanto da Educação Básica.

Destacamos ainda, os tempos e espaços pedagógicos, estrutura física e organização pedagógica e acima de tudo a ampliação urgente da oferta de cursos e disciplinas nos cursos de formação inicial e continuada, pois articulação é uma ação que só se efetivará mediante conhecimentos específicos acerca do tema e esses devem permear todos os docentes envolvidos, um processo que exige movimentos que interrelacionam a formação inicial e continuada dos professores.

\section{REFERÊNCIAS}

ARAÚJO, M. V. de. et al. Formação de professores e inclusão escolar de pessoas com deficiência: análise de resumos de artigos na base SciELO. Rev. psicopedagia. vol.27 $\mathrm{n}^{\circ}$. 84. São Paulo 2010. Disponível em: $<$ file://D:/Users/User/Desktop/forma\%C3\%A7\%C3\%A30\%20inclusao/Forma\%C3\%A 7\%C3\%A3o\%20de $\% 20$ professores $\% 20 \mathrm{e} \% 20$ inclus $\%$ C3\%A3o $\% 20$ escolar $\% 20 \mathrm{de} \% 20 \mathrm{p}$ essoas $\% 20$ com $\% 20$ defici $\%$ C3\%AAncia_\%20an $\%$ C3\%A1lise $\% 20 \mathrm{de} \% 20$ resumos $\% 20 \mathrm{~d}$ e\%20artigos\%20na\%20base\%20SciELO.html>. Acesso em: 01 abr. 2016.

BOGDAN, R.; BIKLEN, S. Investigação qualitativa em educação. Porto: Porto Editora, 1994.

BRASIL. Constituição (1988). Constituição da República Federativa do Brasil. Brasília, DF: Senado Federal: Centro Gráfico, 1988.

BRASIL. Conselho Nacional de Educação. Câmara de Educação Básica. Resolução CNE/CEB n. ${ }^{\circ} 4$, de 2 de outubro de 2009b. Institui diretrizes operacionais para o atendimento educacional especializado na educação básica, modalidade educação especial. Diário Oficial da União, Brasília, 5 out. 2009, Seção 1, p. 17. 
BRASIL. Lei 9.394 de dezembro de 1996. Estabelece as diretrizes e bases da educação nacional. Diário Oficial [da República Federativa do Brasil]. Brasília, 1996. Disponível em: <http://www.planalto.gov.br/ccivil_03/leis/19394.htm>. Acesso em: 12 de maio de 2013.

BUENO, J. G. S. A educação especial nas universidades brasileiras. Ministério da Educação, Secretaria de Educação Especial. Brasília, 2002.

MARCHESI, A. Desenvolvimento e educação de crianças surdas. In: COLL, C.; MARCHESI, A.; PALÁCIOS, J. (Orgs.). Desenvolvimento psicológico e educação: transtornos de desenvolvimento e necessidades educativas especiais. Porto Alegre: Artmed, 2004.

TRIVIÑOS, A. N. S. A Pesquisa Qualitativa em Educação. São Paulo: Atlas, 1990.

VIGOTSKI, L. S. Fundamentos de defectologia. Obras escogidas V. Madrid: Visor, 1997. 